\title{
Pengaruh Metode Tebak Kata Terhadap Peningkatan Keterampilan Berbicara Bahasa Arab Di Madrasah Diniyah Al-Hidayah Gempol Pasuruan
}

\author{
Mufidatul Munawaroh, Syarifuddin \\ Universitas Yudharta Pasuruan \\ mufidatulm@gmail.com, syarifuddin12@gmail.com
}

\author{
Article History: \\ Received: \\ 30 November 2020 \\ Revised: \\ 18 Desember 2020 \\ Accepted: \\ 30 Desember 2020
}

\section{Keywords:}

Word Guess, Speaking Skill

\begin{abstract}
:
Based on observation, students of Madrasah Diniyah Al-Hidayah Gempol Pasuruan are not good enough in mastering Arabic language, especially in speaking skill. Researchers tried to solve the problemby using the Word Guess method. Researchers use the method is to know the influence of the method in speaking skill of students in Madrasah Diniyah Al-Hidayah Gempol Pasuruan. This research is quantative research. The population of this research is all of the 3rd grade students of Madrasah Diniyah Al-Hidayah Gempol Pasuruan. The data collection techniques in this study use observations, interviews, documentation and tests. This study shows that there is influence of the Word Guess method in improving students'speaking skill in Madrasah DiniyahAl-Hidayah Gempol Pasuruan based on the number paired samples statistic of the pretest and the post-test using T-Test.
\end{abstract}

\section{Pendahuluan}

Bahasa digunakan dalam kehidupan sehari-hari untuk sarana komunikasi. Di zaman globalisasi, alangkah baiknya jika seseorang memiliki bahasa asing selain bahasa ibu. Sedikitnya orang dapat menguasai minimal satu bahasa asing untuk dapat mendapatkan informasi global.

Dalam mempelajari bahasa yang dijadikan tujuan utama adalah kemampuan penguasaan berbahasa. Kemampuan penguasaan berbahasa merujuk kepada keahlian yang hubungannya dengan penggunaan bahasa dalam berkomunikasi jelas ${ }^{1}$. Dengan keahlian berbahasa seseorang bisa dijadikan mengungkapkan isi hatinya dan pikiran kepada orang yang lainnya, adapun yang merupakan tujuan penggunaan bahasa adalah untuk berkomunikasi.

Bahasa Arab menjadi salah satu pelajaran bahasa asing yang diajarkan di Madrasah Ibtidaiyah Madrasah Tsanawiyah, Madrasah Aliyah dan juga Madrasah Diniyah. Madrasah Diniyah Al-Hidayah mengajarkan pelajaran bahasa Arab. Dalam pelajaran bahasa Arab ada keterampilan berbahasa yang harus di pelajari yaitu keterampilan mendengar (maharah istima) keterampilan berbicara (maharah kalam), keterampilan membaca (maharah qira'ah) dan keterampilan menulis (maharah kitabah).

\footnotetext{
${ }^{1}$ Abdul Wahab Rosyidi and Mamlu'atul Ni'mah, "Memahami Konsep Dasar Pembelajaran Bahasa Arab” (UINMaliki Press, 2011).
} 
Maharah kalam adalah salah satu keterampilan yang penting. Maharah kalam yaitu keahlian yang menggunakan perasaan dan pikiran atau pendapat yang diungkapkan kepada seseorang/kelompok secara lisan. Maka dari itu guru sebaiknya menggunakan strategi dalam mengajarkannya agar supaya siswa tidak mudah bosan. Imam Makruf mengatakan ada beberapa strategi dalam pembelajaran bahasa Arab yaitu: a). Strategi melatih siswa untuk dapat menceritakan yang mereka lihat dalam berbahasa Arab baik secara lisan maupun secara tulisan b). Strategi kelompok dua orang, strategi ini dipakai lebih mengarahkan seluruh murid, sehingga tiap siswa dapat mendapatkan pengetahuan belajar hasil yang sepadan. Dengan metode yang diterapkan ini peneliti mengharapkan keterampilan atau pengetahuan pelajar dapat merata. c). metode ini diantaranya dibuat untuk mengasah kemahiran anak-anak dalam pemahaamn dan menguasai isi buku bacaan, dan siswa mampu mempratikkan kedalam bentuk gambar. ${ }^{2}$

\section{Tujuan dan Fungsi Berbicara}

Berbicara merupakan gerakan komunikasi lisan yang dapat memberi manfaat bagi lawan bicara, pendengar ataupun masyarakat luas, dan bermanfaat juga untuk pembicara sendiri. Tujuan orang melakukan kegiatan bicara adalah untuk (1) Memanifestasikan dirinya pribadi, (2) Penyesuaian sosial pribadi. $^{3}$

Adapun strategi yang dapat dipergunakan dalam pembelajaran maharah kalam (keterampilan berbicara) adalah sebagai berikut: Khibrat mutsirah, tabir al-ara' al-raisiyah, tamtsiliyyah, ta'bir mushawwar, ya'ab daur al-mudarris, dan jidal fa'aal. ${ }^{4}$

Problematika dalam pembelajaran bahasa Arab dibedakan ke dalam dua aspek, yaitu aspek linguistik dan aspek nonlinguistik. Problematika yang bersifat linguistik di antaranya adalah dalam hal bunyi, kosakata, kalimat dan tulisan. Adapun yang bersifat nonlinguistik seperti yang menyangkut segi sosiobudaya atau yang menyangkut hal-hal yang berhubungan dengan proses pembelajaran di antaranya adalah hal-hal yang menyangkut guru, metode yang dipakai, media, ataupun dari siswa sendiri. ${ }^{5}$ Ada empat dimensi yang minimal harus dikuasai oleh pelajar dalam menguasai bahasa Arab:Fabmul masmu', fabmul maqru', ta'bir syafabi dan ta'bir tabriri. ${ }^{6}$

Metode berawal dari bahasa latin "meta" dimaksud adalah melewati dan "bados" yang dimaksud jalan atau cara. Jalan, aturan, system atau keteraturan (thariqah) sebutan metode dalam bahasa Arab. Sedangkan sebutan metode (method) adalah perencanaan program yang sifatnya menyeluruh yang dapat dihubungankan erat dengan tahapan-tahapan penyampaikan materi pelajaran secara procedural, tidak saling berlawanan, walaupun berlawanan dengan pendekatan.

\footnotetext{
2 Nur Rokhhmatulloh, “Teknik Pembelajaran Maharah Bahasa Arab,” Studi Arab 8, no. 2 (2017): 103-116.

${ }^{3}$ Miftachul Taubah, "Problematika Mahasiswa Dalam Berbicara Bahasa Arab," Studi Arab 5, no. 1 (2014): 23-36.

${ }^{4}$ Syarifuddin Syarifuddin, "Strategi Pembelajaran Maharah Al-Kalam Di Lembaga Pendidikan Bahasa Arab (LPBA)

OCEAN Pare Kediri," Studi Arab 5, no. 1 (2014): 1-22.

${ }^{5}$ Ibid.

6 Taubah, "Problematika Mahasiswa Dalam Berbicara Bahasa Arab."
} 
Langkah-langkah umum tentang penerapan teori ada pada pendekatan tertentu yaitu kata lain dari sebuah metode.

Memakai kata-kata singkat dengan materi bahan ajar dalam bentuk kartu permainan adalah metode tebak kata. Akhirnya siswa dapat mengambil dan menerima pesan dalam belajar Buatlah kartu yang isinya mengandung berbagai macam pertanyaan yang dibutuhkan satu kata jawaban yang bisa mewakili dari semua pertanyaan atau pernyataan yang ada.

Metode tebak kata merupakan pembelajaran yang sangat sederhana. Melalui metode tebak kata siswa dapat mengetahui dan memahami pesan yang didalam pelajaran. Dengan siswa mampu menjawab dan menebak kata siswa dianggap sudah memahami dan menguasai materi pelajaran yang ada. Siswa hanya mengandalkan modal pengetahuannya dan beberapa bekal yang dimiliki siswa untuk bermain metode Tebak Kata ini secara langsung ataupun tidak langsung. Siswa hanya diminta menjawab nama-nama objek dan maksud pada rangkaian kata/kalimat. ${ }^{8}$

Mengarahkan siswa kepada pengetahuan sebagai rambu-rambu yang diberikan sisiwa yang telah diperolehnya sebagai arahan memperoleh pengetahuan baru yang harus mencari sendiri yakni susunan kata dan kalimat. Proses berdiskusi telah diteguhkan dalampencarian sumber dengan acuan berdiskusi berkelompok dengan teman sekelas.

Model dan aplikasi metode tebak kata bermacam-macam, model sendiri-sendiri, model berpasangan dan model serempak. Adapun dari masing-masing model tidak sama, ${ }^{9}$ antara lain:

a. Model serempak dalam metode tebak kata : 1)Pengetahuan dasar yang disampaikan oleh gurunya. 2)belajar materi pelajaran yang sudah sesuai dengan kurikulum yang berlaku agar siswa mempelajarinya. 3)Petunjuk sesuai dengan materi pelajaran kata dan kalimatnya yang sudah disiapkan oleh guru. 4)Materi pelajaran yang wajib dikuasai siswa menyelaraskan banyaknya siswa dikelas tersebut. 5)Susunan kartu dan kertas ada rangkaian kata dan kalimat. 6) Kata atau kalimat yang mengandung arti tertentu yang didalam kartu guru wajib memperlihatkannya. 7) Kartu yang selesai dijawab langsung dilanjutkan dengan kartu selanjutny sampai kartu sudah terjawab semua. ${ }^{10}$

b. Model berpasangan dalam metode Tebak Kata terdiri dari dua siswa: 1) Pengetahuan dasar yang disampaikan oleh gurunya. 2) belajar materi pelajaran yang sudah sesuai dengan kurikulum yang berlaku agar siswa mempelajarinya. 3) Petunjuk sesuai dengan materi pelajaran kata dan kalimatnya yang sudah disiapkan oleh guru. 4) Rangkaian kata atau kalimat yang sesuai dari arahan petunjuk disusun dalam sebuah kartu atau kertas,

\footnotetext{
${ }^{7}$ Acep Hermawan and Chaedar Alwasilah, Metodologi Pembelajaran Bahasa Arab (PT Remaja Rosdakarya, 2011).

${ }^{8}$ Zainal Aqib and Ali Murtadlo, Kumpulan Metode Pembelajaran: Kreatif Dan Inovatif (Bandung: Sarana Tutorial Nurani Sejahtera, 2016).

9 Jasa Ungguh Muliawan, 45 Model Pembelajaran Spektakuler (Yogyakarta: Ar-Ruzz Media, 2016).

${ }_{10}$ Monica Bonnie Anizar, "Penggunaan Metode Tebak Kata Untuk Meningkatkan Keterampilan Berbicara Bahasa

Prancis Siswa Kelas X IIS 1 SMA Negeri 7 Purworejo” (Universitas Negeri Yogyakarta, 2017).
} 
sedangkan jawabannya ditulis dalam bentuk kartu/kertas yang berbeda yang telah disediakan. $^{11}$

c. Model sendiri-sendiri dalam metode Tebak Kata: 1) Pengetahuan dasar yang disampaikan oleh gurunya. 2) belajar materi pelajaran yang sudah sesuai dengan kurikulum yang berlaku agar siswa mempelajarinya. 3)Petunjuk sesuai dengan materi pelajaran kata dan kalimatnya yang sudah disiapkan oleh guru. 4) Didalam kartu/kertas sudah terdapa rangkaian kata/kalimat. 5)Materi pelajaran yang wajib dikuasai siswa menyelaraskan banyaknya siswa dikelas tersebut. 6)Siswa untuk maju secara bergilir satu-satu untuk menjawab kartu yang sudah menjadipetunjuk yang diberikan. 7) Ketika siswa gagal dalam menebak kata siswa lain diperbolehkan memberikan bantuan jawaban atau hanya petunjuk saja. $^{12}$

d. Metode Tebak Kata seperti halny metode lain juga mempunyai kelebihan dan kelemahan pembelajaran. Adapun kelebihan metode Tebak Kata yaitu: a) Pembelajaran yang diterapkan lebih menarik siswa untuk belajar karena memakai metode kartu sehingga siswa tidak mudah bosan. b) Meningkatkan daya ingat dan pikiran siswa lebih tajam. karena siswa dituntut untuk bisa menjawab pertanyaan yang membutuhkan pikiran kritis.

c) Pembelajaran akan lebih menyenangkan dan berkesan. ${ }^{13}$ Selain kelebihan, metode pembelajaran Tebak Kata juga memiliki kekurangan, diantaranya sebagai berikut : a) Bersifat aturan. b) Membutuhkan kerja keras dan keahlian pribadi. c) Tidak mudah siswa membuat kartu yang menarik untuk dicermati siswa

\section{Metode}

Jenis penelitian yang dipakai adalah pendekatan Kuantatif dengan menggunakan jenis penelitian eksperimen quasy.Penelitian ini tidak menggunakan kelas pembanding namun menggunakan hasil tes siswa, Rancangan penelitian yang dilakukan dalam penelitian ini, yaitu : a). Merumuskan tentang masalah penelitian dan menentukan cara tujuan survei. Peneliti dapat menentukan sebuah judul secara sesuai dengan masalah yang akan dibahas, yaitu "metode tebak kata digunakan untuk meningkatkan maharah kalam di Madrasah Diniyah Al-Hidayah Bulusari Gempol Pasuruan” b). Lalu peneliti melakukan mengunjungi lokasi dan melakukan pendekatan. c). Pengambilan sampel yaitu santri madrasah diniyah Al-Hidayah kelas tiga. d). Wawancara dengan guru mata pelajaran dan beberapa siswa dikelas tiga di Madrasah Al-Hidayah Bulusari Gempol Pasuruan e). Melakukan observasi seputar kegiatan guru dalam penggunaan metode

\footnotetext{
11 Muliawan, 45 Model Pembelajaran Spektakuler.

12 Anizar, "Penggunaan Metode Tebak Kata Untuk Meningkatkan Keterampilan Berbicara Bahasa Prancis Siswa Kelas X IIS 1 SMA Negeri 7 Purworejo."

${ }^{13}$ Aqib and Murtadlo, Kumpulan Metode Pembelajaran: Kreatif Dan Inovatif.
} 
pembelajaran. f). Menetapkan konsep dan menentukan kepustakaan metode dan hasil pembelajaran. g). Pre-test h). Treatment i). Postest j). Pekerjaan lapangan (wawancara dan dokumentasi). k). Pengolahan data

Adapun ruang lingkup yang ada dalam penelitian ini adalah sebagai berikut : a)Penelitian hanya dilakukan di Madrasah Diniyah Al-Hidayah Pelem Bulusari tahun 2019 dan yang mejadi informan adalahkepala madrasah, wali kelas dan santri kelas III.b)Dalam proses pembelajaran diketahui ada berbagai macam-macam cara yang berbeda-beda, dalam segi aspek materi metode ataupun segi aspek tujuan dan pengubahan tingkah lakunya yang diharapkan. Namun peneliti hanya meneliti metode yang diterapkan dalam pembelajaran Tebak Kata di Madrasah Diniyah AlHidayah Pelem Bulusari tahun 2019 dan juga hal-hal yang menjadi faktor penghambat dan pendukung pembelajaran Tebak Kata bahasa Arab.

Teknik pengumpulan data yang digunakan adalah: a). Observasi b). Wawancara c). Dokumentasi d). Tes, dan untuk teknik analisis menggunakan hasil tes pretest dan posttest dengan menggunakan SPSS.

\section{Hasil dan Pembahasan}

Hasil perhitungan nilai pretest dan posttest penelitian yang sudah dilakukan, untuk datadata hasil penilaian SPSS sebagai berikut:

Dari hasil penelitian, menggunakan metode Tebak Kata dalam mengajar bahasa Arab terbukti sangat efektif. Siswa menjadi tertarik belajar bahasa Arab yang awalnya kurang tertarik. Dengan menggunakan metode ini siswa akhirnya bisa berbicara bahasa Arab. Hal ini karena belajar bahasa Arab dengan menggunakan metode Tebak Kata dibuat dengan sangat menyenangkan mungkin. Selama ini menurut siswa belajar bahasa Arab cenderung membosankan dan monoton karena tanpa metode menarik. Dengan kata lain belajar dengan menggunakan metode tebak kata dapat meningkatkan kualitas maharah kalam bahasa Arabpara siswa.Indikatornya adalah: Pertama, hasil penelitian siswa lebih baik dari sebelumnya, meskipun masih ada yang mendapatkan nilai dibawah rata-rata ketika tes akhir. Kedua, hasil tanya jawab yang dilakukan oleh peneliti dengan macam-macam subjek, yaitu siswa, guru dan kepala madrasah diniyah Al-Hidayah. Siswa merasa senang karena kosakatanya bertambah. Guru juga berpendapat ketika guru memakai metode dan strategi yang bervariasi, para siswa akan merasa senang salah satunya dengan metode tebak kata ini. Kepala madrasah menyampaikan dengan adanya metode tebak kata, terlihat ada perbedaan sikap dari para siswa Ketiga, hasil observasi didalam kelas saat proses pembelajaran. Hasil obeservasi menunjukkan bahwa mereka juga sangat antusias berpartisipasi dalam kegiatan belajar bahasa Arab dengan metode Tebak Kata ini, dan juga para siswa lebih mudah dalam memahami kosakata. 
Kegiatan ini dilakukan pada siswa kelas III di madrasah diniyah Al-Hidayah Gempol Pasuruan. Sampel dalam penelitian ini adalah seluruh siswa kelas III tahun 2019/2020 dengan jumlah 13 siswa. Dalam penelitian ini peneliti memperoleh data dari hasil tes siswa yakni pretest dan posttest. Pretest adalah tes yang diberikan kepada siswa sebelum mereka mendapatkan perlakuan. Sedangkan posttest adalah tes yang dilakukan setelah siswa mendapatkan perlakuan. Dari hasil keduanya peneliti dapat membandingkannya hasil pretest dan posttest.

\begin{tabular}{ccc}
\hline \multirow{2}{*}{ NO } & \multicolumn{2}{c}{ JENIS TES } \\
\cline { 2 - 3 } & PRETEST & POSTTEST \\
\hline 1 & 80 & 100 \\
\hline 2 & 70 & 90 \\
\hline 3 & 50 & 100 \\
\hline 4 & 60 & 100 \\
\hline 5 & 60 & 80 \\
\hline 6 & 60 & 90 \\
\hline 7 & 60 & 85 \\
\hline 8 & 60 & 100 \\
\hline 9 & 40 & 70 \\
\hline 10 & 50 & 80 \\
\hline 11 & 60 & 100 \\
\hline 12 & 75 & 100 \\
\hline 13 & 30 & 70 \\
\hline
\end{tabular}

Paired Samples Test

\begin{tabular}{|c|c|c|c|c|c|c|c|c|c|}
\hline \multicolumn{10}{|c|}{ Paired Samples Test } \\
\hline \multicolumn{7}{|c|}{ Paired Differences } & \multirow[b]{3}{*}{$t$} & \multirow[b]{3}{*}{ df } & \multirow[b]{3}{*}{ Sig. (2-tailed) } \\
\hline & & \multirow[b]{2}{*}{ Mean } & \multirow[b]{2}{*}{ Std. Deviation } & \multirow{2}{*}{$\begin{array}{l}\text { Std. Error } \\
\text { Mean }\end{array}$} & \multicolumn{2}{|c|}{$\begin{array}{l}\text { 95\% Confidence Interval of the } \\
\text { Difference }\end{array}$} & & & \\
\hline & & & & & Lower & Upper & & & \\
\hline Pair 1 & Pretest-Postest & $-28,46154$ & 7,18349 & 1,99234 & $-32,80248$ & $-24,12060$ & $-14,285$ & 12 & .000 \\
\hline
\end{tabular}

Dari hasil rumusan masalah adalah jika probabilitas $>0,05$, maka Ho dapat diterima dan Ha ditolak, jika probabilitas hasil < 0,05 Ho ditolak dan Ha diterima hasil perhitungan akhir dari penelitian ini adalah menggunakan spss, menunjukkan bahwa hasilnya signifikan. 


\section{Kesimpulan}

Berdasarkan observasi pembelajaran bahasa Arab di Madrasah Diniyah Al-Hidayah Gempol Pasuruan masih belum efektif, maka dari itu, peneliti bereksperimen dengan menggunakan metode tebak kata untuk siswa Madrasah Diniyah Al-Hidayah Gempol Pasuruan kelas III. Pendekatan kuantatif dan experiment quasy digunakan dalam penelitian ini. Hasil penelitian dengan menggunakan T-test menunjukkan bahwa metode tebak kata mempunyai pengaruh signifikan dalam meningkatkan keterampilan maharah kalam siswa Madrasah Diniyah Al-Hidayah Gempol Pasuruan. 


\section{Daftar Pustaka}

Anizar, Monica Bonnie. "Penggunaan Metode Tebak Kata Untuk Meningkatkan Keterampilan Berbicara Bahasa Prancis Siswa Kelas X IIS 1 SMA Negeri 7 Purworejo.” Universitas Negeri Yogyakarta, 2017.

Aqib, Zainal, and Ali Murtadlo. Kumpulan Metode Pembelajaran: Kreatif Dan Inovatif. Bandung: Sarana Tutorial Nurani Sejahtera, 2016.

Hermawan, Acep, and Chaedar Alwasilah. Metodologi Pembelajaran Bahasa Arab. PT Remaja Rosdakarya, 2011.

Muliawan, Jasa Ungguh. 45 Model Pembelajaran Spektakuler. Yogyakarta: Ar-Ruzz Media, 2016.

Rokhhmatulloh, Nur. "Teknik Pembelajaran Maharah Bahasa Arab." Studi Arab 8, no. 2 (2017): 103-116.

Rosyidi, Abdul Wahab, and Mamlu'atul Ni'mah. "Memahami Konsep Dasar Pembelajaran Bahasa Arab." UIN-Maliki Press, 2011.

Syarifuddin, Syarifuddin. "Strategi Pembelajaran Maharah Al-Kalam Di Lembaga Pendidikan Bahasa Arab (LPBA) OCEAN Pare Kediri." Studi Arab 5, no. 1 (2014): 1-22.

Taubah, Miftachul. "Problematika Mahasiswa Dalam Berbicara Bahasa Arab." Studi Arab 5, no. 1 (2014): 23-36. 